\title{
Housing environments and the barpressing vs freeloading phenomenon in rats*
}

\author{
ROBERT D. TARTE, STEVEN G. TOWNSEND \\ and \\ CHARLES R. VERNON \\ University of Nevada, Las Vegas, Nev. 89154
}

\begin{abstract}
Animals housed in four environmental conditionsstimulus-enriched, motor-enriched, stimulus-deprived, and control-were tested for their preference in a choice situation in which they could obtain food pellets by barpressing or from a free dish. Results indicated that animals in the control and motor-enriched groups barpressed for more food than they took freely, while animals in both the stimulus-enriched and the stimulusdeprived groups preferred to freeload. Explanations of the seemingly paradoxical results are discussed in terms of differences in novelty between the housing environments and the testing situation.
\end{abstract}

Studies examining the effects of an enriched or deprived living environment upon later learning tasks have been abundant in recent years. Forgays \& Forgays (1952) found that animals reared in a "free" environmental situation performed significantly better on the Hebb-Williams test than animals housed in standard laboratory cages. Since then, studies by Woods, Fiske, \& Ruckelhaus (1961) and Montgomery \& Zimbardo (1957) have attempted to examine the role of exploratory drive in respect to similar findings. Results of the above studies have indicated that animals reared in enriched environments show increased exploratory behavior.

In a series of studies since 1950, Rosenzweig, Bennett, Diamond, and Kretch demonstrated the effects of an enriched environment on brain anatomy and chemistry (Rosenzweig, Bennett, \& Diamond, 1972). They found that rats kept in an enriched environment for 30 days or more showed a distinct increase in the weight of the cerebral cortex, a greater thickness of the cortex, and a greater total activity of acetylcholinesterase and cholinesterase compared to animals kept in an impoverished environment.

It was with the above findings in mind that this experiment was designed. The question was raised as to how such environmental differences might affect the behavior of rats in the barpressing vs freeloading phenomenon. Rats will obtain some food pellets singly by pressing a lever in the presence of identical massed free food and, under certain conditions, prefer to obtain food by barpressing rather than by taking it freely from a filled dish (Jensen, 1963; Neuringer, 1969; Carder \& Berkowitz, 1970; Carder, 1972; Tarte \& Snyder, 1972). Explanations of this phenomenon have mainly been

*This research was supported by a grant from the University of Nevada to the first author. Requests for reprints should be sent to Robert D. Tarte, Department of Psychology, University of Nevada, Las Vegas, Nevada 89154. restricted to the idea of an intrinsic attractiveness in barpressing (Jensen, 1963) and to the hypothesis that barpressing completes the consummatory pattern for rats unable to manipulate their food in the operant situation (Carder, 1972).

In light of these explanations and the results of the enriched-deprived environment studies, it was hypothesized that rats housed in an enriched environment would barpress more in the presence of free food than animals housed in a control or deprived situation, primarily due to an increased exploratory drive.

\section{METHOD \\ Subjects}

Eighteen male albino rats, each weighing approximately $100 \mathrm{~g}$ at the beginning of the experiment, were used as Ss. The animals were assigned randomly to one of three experimental groups and a control group. The stimulus-enriched group contained eight animals, the motor-enriched group contained two animals, and the stimulus-deprived and control groups each contained four animals. All rats used in the study were experimentally naive and had previously been housed in standard laboratory cages.

\section{Apparatus}

The enriched environment consisted of a $122 \times 122 \times 30 \mathrm{~cm}$ wooden box with a chicken-wire top. A sandpile, approximately $20 \mathrm{~cm}$ high, covered one half of the floor and a variety of objects, including wooden blocks, balls, plastic toys, and tunnels made of tin cans and wood, were scattered randomly around the box. A small $18 \times 25 \times 34 \mathrm{~cm}$ mouse cage was introduced to the environment after the experiment was under way as an additional stimulus item. Two water bottles extended through the side of the box, and food was obtained from a metal dish attached to one wall.

The motor-enriched environments consisted of two single-animal Lafayette activity wheels, each having a counter that recorded the number of revolutions made by the animals living in the activity-wheel cage.

The control animals were housed two to a cage in standard $18 \times 18 \times 24 \mathrm{~cm}$ laboratory cages.

The stimulus-deprived environments were adaptations of the standard control cages. A piece of fiberboard divided the cages in half lengthwise, thus forming two modules, each half the size of the original cage $(18 \times 9 \times 24 \mathrm{~cm})$. A wire food hopper, used to restrict food manipulation, was fitted to the front of each module along with a water bottle. Each animal was housed one to a module.

All testing took place in Lehigh Valley operant chambers. During training and choice days, food reinforcers in the form of 45-mg Noyes pellets were obtained for each press of a bar located in the front right portion of the chamber. Free food was available during the free and choise days from a metal dish containing 400 pellets in the right rear portion of the chamber.

\section{Procedure}

On Day 1 of the study, the animals were assigned randomly to one of the four environments, where they remained for 66 days. including the final 12 days of testing. Food manipulation was possible for all animals except those in the deprived environments. The stimulus-enriched animals were handled of ten by different persons throughout the study, while the control. 
Table 1

Mean Pellets Consumed Per Animal Per Day During All Days of Testing

\begin{tabular}{|c|c|c|c|c|c|c|}
\hline \multirow[b]{2}{*}{ Group } & \multirow[b]{2}{*}{$\mathbf{N}$} & \multirow{2}{*}{$\begin{array}{c}3 \text { Free } \\
\text { Reward } \\
\text { Days }\end{array}$} & \multirow{2}{*}{$\begin{array}{c}6 \text { Barpress } \\
\text { Training } \\
\text { Days }\end{array}$} & \multicolumn{2}{|c|}{2 Choice Days } & \multirow[b]{2}{*}{$\begin{array}{l}\text { Percent } \\
\text { Via Bar }\end{array}$} \\
\hline & & & & $\begin{array}{l}\text { Taken } \\
\text { Freely }\end{array}$ & $\begin{array}{c}\text { Taken } \\
\text { Via Bar }\end{array}$ & \\
\hline Control & 4 & 212.3 & 208.7 & 57.0 & 182.8 & 76.2 \\
\hline Motor Enriched & 2 & 171.5 & 219.7 & 115.0 & 181.5 & 61.2 \\
\hline Stimulus Enriched & 8 & 326.3 & 265.1 & 257.4 & 104.0 & 28.8 \\
\hline Stimulus Deprived & 4 & 252.9 & 248.5 & 221.7 & 48.3 & 17.9 \\
\hline
\end{tabular}

motor-enriched, and stimulus-deprived animals were never handled except in the experimental sessions. On Day 48, 7 days prior to testing, the rats were placed on a food-deprivation schedule in which they received food for $1 \mathrm{~h}$ per day. The testing procedure followed the design of Carder \& Berkowitz (1970), in which food was freely available to the animals for the first 3 days in the operant chambers for $1 \mathrm{~h}$ with the bars removed from the chambers. The following 6 days consisted of barpress training for $1 \mathrm{~h}$ per day, with no free food available. On the 10th and 11 th days, free food was again present in the chamber and the animal could obtain pellets by barpressing or freely from the dish. The amount of food taken freely and by barpressing was recorded. after which all animals received $1 / 2 h$ of food in their respective home environments.

\section{RESULTS}

Mean amounts of food consumed during the free, training, and choice conditions and the percentage of reinforcer taken via barpressing during the choice days are shown in Table 1. Control animals barpressed for a higher percentage of food than any other group. This percentage is approximately the same as that found in previous studies (Carder \& Berkowitz, 1970; Tarte \& Snyder, 1972) for control animals. It is also apparent that the stimulus-enriched and the stimulus-deprived groups both preferred to take free food. The greatest range of individual differences during the choice days was found in the enriched group, in which animals ranged from $6 \%$ to $80 \%$ of pellets obtained via the bar. The stimulus-deprived group ranged from $2 \%$ to $44 \%$. The differences obtained from the remaining two groups were minimal.

A one-way analysis of variance for treatment groups, using percentage of food obtained via barpressing, showed a significant difference between the groups $(F=6.94, \mathrm{df}=3 / 17, \mathrm{p}<.01)$. This indicates that differences in percentages were found as a result of the different environmental conditions. A Newman-Keuls test showed that the percentages of barpressing of both groups that preferred to barpress (control and motor-enriched) were significantly different at less than the .05 level from both of the groups that preferred to take free food (stimulus-enriched and stimulus-deprived).

\section{DISCUSSION}

It was hypothesized that animals housed in an enriched environment would barpress for a greater percentage of food in the presence of free food than would animals housed in a stimulus-deprived environment or a normally housed control group. The data show, however. that control animals had the greatest percentage and that the stimulus-enriched animals preferred to freeload. These results are inconsistent with the previous study, which suggested that animals reared in an enriched environment would have an increased exploratory drive (Woods, Fiske, \& Ruckelhaus, 1961), if it can be assumed that the exploratory drive is a factor involved in barpressing in the presence of free food. Studies by Zimbardo \& Montgomery (1957) and Konrad \& Bagshaw (1970) suggest, however, that novelty in the test situation has a large impact upon the exploratory drive of animals reared in restricted or enriched environments. These findings offer a possible explanation for the results of the present study, if the differences in novelty between the testing situation and the four environments are compared. Control animals would have a large exploratory drive due to the large difference in novelty. The enriched animals would have a much smaller exploratory drive, as the novelty of the test situation would be small compared to their enriched housing environment. This notion is substantiated by Zimbardo \& Montgomery (1957), who found that animals reared in a free environment explored less in a simple $\mathrm{Y}$ maze than normally reared rats. The apparent contradiction in results that found both the stimulus-enriched and the stimulus-deprived animals preferring free food might be clarified by a study that found cats housed in a deprived environment showing greatly inhibited behavior in a testing situation due to the large difference in novelty between the housing environment and the testing situation (Konrad \& Bagshaw, 1970). Thus, in the present study, the difference in novelty for the stimulus-deprived animals was so extreme that their actions were inhibited, resulting in a greatly reduced exploratory drive. What is hypothesized, then, is an inverted-U function in which exploratory behavior or, specifically in this case, barpressing in the presence of free rewards is related to the amount of difference between the home environment and the testing situation. There is an optimal level of novelty or complexity. The fact that animals are normally housed in a way that generates high levels of barpressing in the presence of free rewards may be fortuitous in terms of the phenomenon. The notion presented here is related to a number of previous hypotheses, including those of Hebb (1955), Berlyne (1960), Walker (1964), and others, concerning optimal arousal and complexity levels.

\section{REFERENCES}

Berlyne, D. E. Conflict, arousal, and curiosity. New York: McGraw-Hill, 1960.

Carder, B. Rats' preference for earned in comparison with free liquid reinforcers. Psychonomic Science, 1972, 26, 25-26.

Carder, B. \& Berkowitz, K. Preference for earned food in relation to free food. Science, $1970,167,1273-1274$.

Forgays, D., \& Forgays, J. The nature of the effect of free-environment experience in the rat. Journal of Comparative \& Physiological Psychology, 1952, 45, 322-328.

Hebb, D. O. Drives and the C.N.S. (conceptual nervous system). Psychological Review, 1955, 62, 243-254.

Jensen, G. D. Preference for bar pressing over "freeloading" as a function of number of rewarded presses. Journal of Experimental Psychology, 1963, 65, 451-454.

Konrad, K., \& Bagshaw, M. The effect of novel stimuli on cats 
reared in a restricted environment. Journal of Comparative \& Physiological Psychology, 1970, 70, 157-164.

Montgomery, K., \& Zimbardo, P. Effect of sensory and behavioral deprivation upon exploratory behavior in the rat. Perceptual \& Motor Skills, 1957, 7, 223-229.

Neuringer, A. J. Animals respond for food in the presence of free food. Science, 1969, 166, 399-401.

Rosenzweig, M. R., Bennett, E. L., \& Diamond, M. C. Brain changes in response to experience. Scientific American, 1972, 226, 22-29.

Tarte, R. D., \& Snyder, R. L. Barpressing in the presence of free food as a function of food deprivation. Psychonomic Science $1972,26,169-170$

Walker, E. L. Psychological complexity as a basis for a theory of motivation and choice. In D. Levine (Ed.), Nebraska symposium on motivation Lincoln, Nebr: University of Nebraska Press, 1964. Pp. 47-96.

Woods, P. J., Fiske, A. S., \& Ruckelhaus, S. I. The effects of drives conflicting with exploration on the problem-solving behavior of rats reared in free and restricted environments. Journal of Comparative \& Physiological Psychology, 1961, 54, 167-169.

Zimbardo, P. G., \& Montgomery, K. C. Effects of "free" environmental rearing upon exploratory behavior. Psychological Reports, 1957, 3,589-594.

(Received for publication May 10, 1973.)

\section{The effects of discrimination training on the recognition of white and oriental faces}

\section{ELAINE S. ELLIOTT, ELIZABETH J. WILLS and}

ALVIN G. GOLDSTEIN

University of Missouri, Columbia, Mo. 65201

Recognition for faces of whites and orientals was investigated using white Ss at a predominantly white university. Ss who participated in a discrimination training, or practice, session involving a paired-associate (PA) task with oriental faces scored significantly higher on a subsequent recognition test involving oriental faces than did Ss who received no practice or Ss who received practice involving white faces. Ss who practiced with white faces did not score significantly higher on the recognition test than Ss without practice or Ss who saw oriental faces during the practice session. These results lend support to a differential experience hypothesis, with the possibility of schema functioning as a mediator of differential experience.

Maplass \& Kravitz (1969) attempted to demonstrate differential recognition performance for faces of own and other race among both white and black Ss from a 